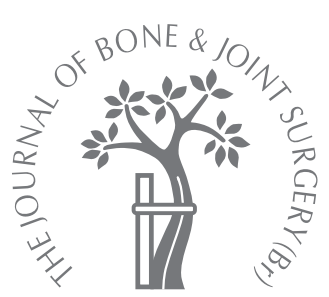

M. Honl,

K. Schwieger,

M. Salineros,

J. Jacobs,

M. Morlock,

M. Wimmer

From Rush

University Medical

Centre, Chicago,

Illinois, USA

\title{
Orientation of the acetabular component
}

\author{
A COMPARISON OF FIVE NAVIGATION SYSTEMS WITH \\ CONVENTIONAL SURGICAL TECHNIQUE
}

M. Honl, Dr. med, Dr. Ing.habil, Professor, Orthopaedic Surgeon Department of Orthopaedic Surgery, LKH Klagenfurt, A9020 Klagenfurt, St. Veiter Strasse 47, Carinthia, Austria.

K. Schwieger, Dr. Ing, Group Leader

AO Research Institute,

Clavadelerstrasse 8, CH-7270

Davos Platz, Switzerland.

M. Salineros, MD,

Orthopaedic Surgeon

J. Jacobs, MD, Professor,

Orthopaedic Surgeon

M. Wimmer, Dr. Ing,

Professor, Director of Tribology

Rush University Medical

Center, 1653 W. Congress

Parkway, AcFac 726b, Chicago,

Illinois 60612, USA

M. Morlock, Dr. habil, PhD,

Professor, Director of

Biomechanics

Biomechanics Section

TU Hamburg-Harburg,

Denickestrasse 15, D-21073,

Hamburg, Germany.

Correspondence should be sent to Professor M. Honl; e-mail: matthias.honl@lkh-klu.at

(C)2006 British Editorial Society of Bone and Joint Surgery doi:10.1302/0301-620X.88B10. $17587 \$ 2.00$

$J$ Bone Joint Surg [Br]

2006;88-B:1401-5.

Received 29 December 2005;

Accepted after revision 18 May 2006

We compared the orientation of the acetabular component obtained by a conventional manual technique with that using five different navigation systems.

Three surgeons carried out five implantations of an acetabular component with each navigation system, as well as manually, using an anatomical model. The orientation of the acetabular component, including inclination and anteversion, and its position was determined using a co-ordinate measuring machine.

The variation of the orientation of the acetabular component was higher in the conventional group compared with the navigated group. One experienced surgeon took significantly less time for the procedure. However, his placement of the component was no better than that of the less experienced surgeons. Significantly better inclination and anteversion ( $p<0.001$ for both) were obtained using navigation. These parameters were not significantly different between the surgeons when using the conventional technique $(p=0.966)$.

The use of computer navigation helps a surgeon to orientate the acetabular component with less variation regarding inclination and anteversion.

Correct orientation of the acetabular component including inclination and anteversion, and the exact positioning of its centre are important factors for the outcome of total hip replacement (THR). Dislocation, ${ }^{1-5}$ increased wear ${ }^{4-6}$ and impingement ${ }^{7-10}$ can be caused by misalignment.

Computer-assisted surgery is increasingly being used to optimise the positioning of components. ${ }^{11-15}$ Minimally-invasive surgery may allow a restricted view, and calls for intraoperative imaging, ${ }^{16-19}$ or computer-assisted surgery. ${ }^{20-22}$

Active systems (robotic) were popular in Europe for reaming the femur in the mid1990s but the early clinical results did not justify their widespread use. ${ }^{23}$ Passive navigation systems provide the surgeon with information about the position of instruments or components within a reference system. The system allows the surgeon to work within a virtual anatomy. ${ }^{24-27}$

There are two different types of navigation system, image-based and image-free. Imagebased systems require CT images to be obtained pre-operatively ${ }^{28}$ which are then registered with the three-dimensional (3D) co-ordinates of the patient and the virtual image. Fluoroscopic images obtained intra-operatively can also be used. ${ }^{27}$ Image-free systems are based on kinematic data or point-clouds that are acquired intra-operatively. ${ }^{24,25,29,30}$ Computerassisted navigation systems using the pointcloud points make a 3D reconstruction image that can be explored on a computer screen.

There are few studies that show an improvement in placement of the acetabular component using computer-assisted surgery, and these have small numbers of patients or samples. ${ }^{27,29,31}$ It is not known whether the use of computer-assisted surgery improves accuracy when used by different surgeons or if imagebased $^{31-37}$ or image-free systems $s^{24,25,38-41}$ yield different results.

The aim of our study was to compare the orientation and position of acetabular components using different computer-assisted surgery systems, and the conventional surgical technique.

\section{Materials and Methods}

We used five different systems of computerassisted surgery: Navitrack image-free (Zimmer, Warsaw, Indiana), Navitrack image-based (Zimmer), Orthopilot (image-free; Aesculap, Tuttlingen, Germany), VectorVision (imagebased; Brainlab, Munich, Germany) and Surgetics-Station (image-free; Praxim-Medivision, Bern, Switzerland). We performed CT scans of 


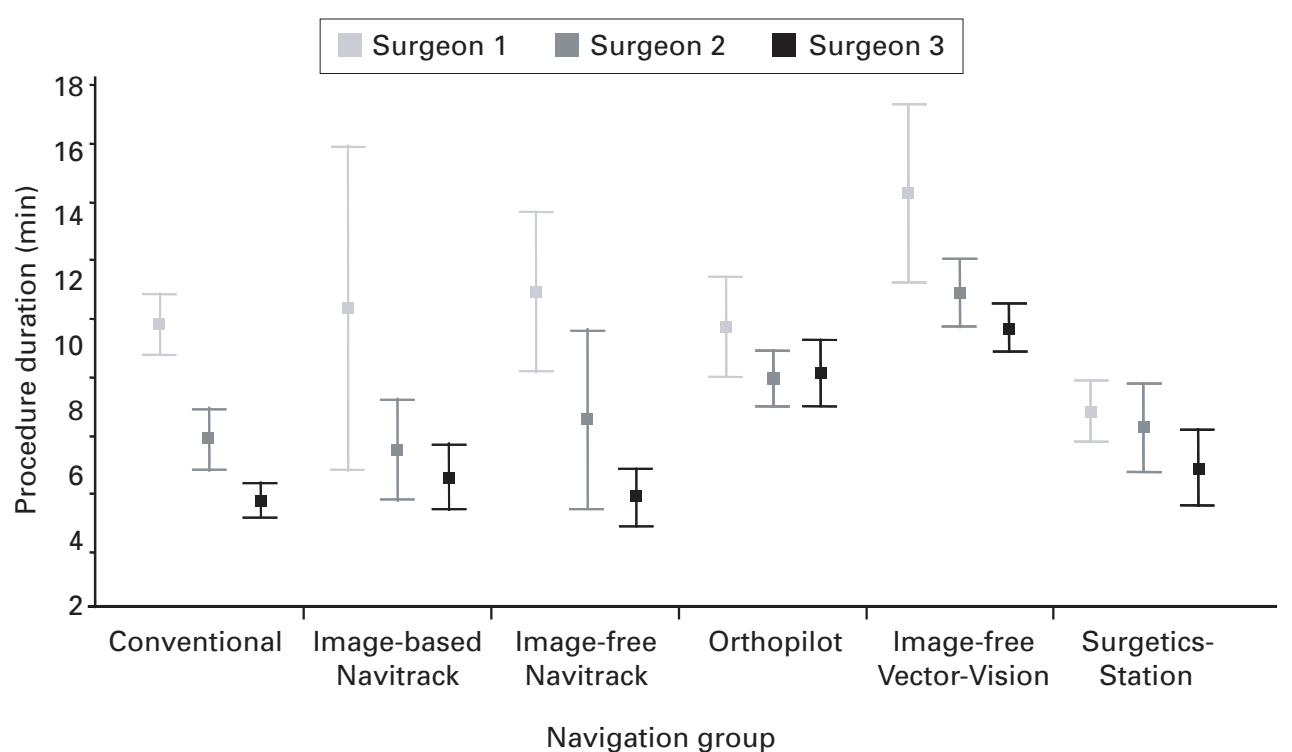

Fig. 1

Graph showing the procedure duration vs surgeon and navigation-group.

the pelvis of a female cadaver, according to the manufacturer's specifications. A rectangular block, including the left acetabulum, was removed from the pelvis. The whole block was then moulded in silicone (Elastosil, Wacker-Chemie $\mathrm{GmbH}$, Bughausen, Germany) and 90 acetabular components of polyurethane foam (Bayer AG, Leverkusen, Germany) were made. The advantage of using these acetabula was that there was no variation in the anatomical features or material properties, as would have occurred with cadaver specimens.

The acetabula were placed in a dummy that was similar to a real patient in height and volume, to match the proportions and the position on an operative table. To make the model more realistic a femur, after resection of the head, was inserted into the thigh and soft foam was used to represent the capsule. The dummy was draped and positioned supine on an operating table. A new model of the acetabulum was placed in the pelvis and the dummy repositioned before each implantation. The model of the acetabulum was a tight press-fit in the pelvis and therefore the position and orientation of the model was the same for each implantation.

Three surgeons with no previous experience of computer-assisted surgery undertook the surgery following training by a company representative from each of the manufacturers. Surgeon 1 was a resident in the second year of training who had previously implanted ten hips; surgeon 2 was a consultant who had performed 70 THRs and surgeon 3 was a consultant who had performed 480 THRs. The authors did not participate in the surgery.

An angle of inclination of $30^{\circ}$ with $10^{\circ}$ of anteversion was chosen for each acetabulum. The company representa- tives performed the calibration, point acquisition and registration for each acetabulum, in order to eliminate inappropriate use of the systems. The different systems of computer-assisted surgery used different acetabular components and therefore, four different spherical press-fit components had to be used.

We used Allofit (Zimmer), Plasma-Cup (Aesculap), Duraloc (DePuy, Warsaw, Indiana) and Kaputziner (ESKA, Lübeck, Germany) components, all of $56 \mathrm{~mm}$ in diameter. None of the surgeons had implanted these components previously, but all used spherical press-fit prostheses in their routine clinical practice. Each surgeon implanted five system-specific components using a conventional technique, and five components using computer-assisted surgery. The operations were carried out in a random order decided by a random number generator (SPSS 11.5, Munich, Germany). The surgeons had full access to the navigational tools until the component had been positioned, but were prevented from using the orientation-confirmation tool within the programme. Each surgeon was asked to estimate the orientation that had been achieved. The time taken for the surgery was recorded.

The acetabular model was mounted on a co-ordinate measuring machine (Mitutoyo, Neuss, Germany). ${ }^{12}$ The angles of inclination and anteversion were measured with an accuracy of SD $0.5^{\circ}$. The craniocaudal (x), the mediolateral $(\mathrm{y})$ and the anteroposterior $(\mathrm{z})$ positions were determined with an accuracy of SD $0.1 \mathrm{~mm}$. These co-ordinates were used to determine the length of the malposition vector: $\left.\sqrt{ }\left(\mathrm{x}-\mathrm{x}_{\mathrm{o}}\right)_{3}+\left(\mathrm{y}-\mathrm{y}_{0}\right)^{2}+\left(\mathrm{z}-\mathrm{z}_{0}\right)^{2}\right)=$ malposition vector.

Statistical analysis. Analysis of variance (ANOVA) was calculated using SPSS version 11.5 (SPSS, Munich, Germany). 


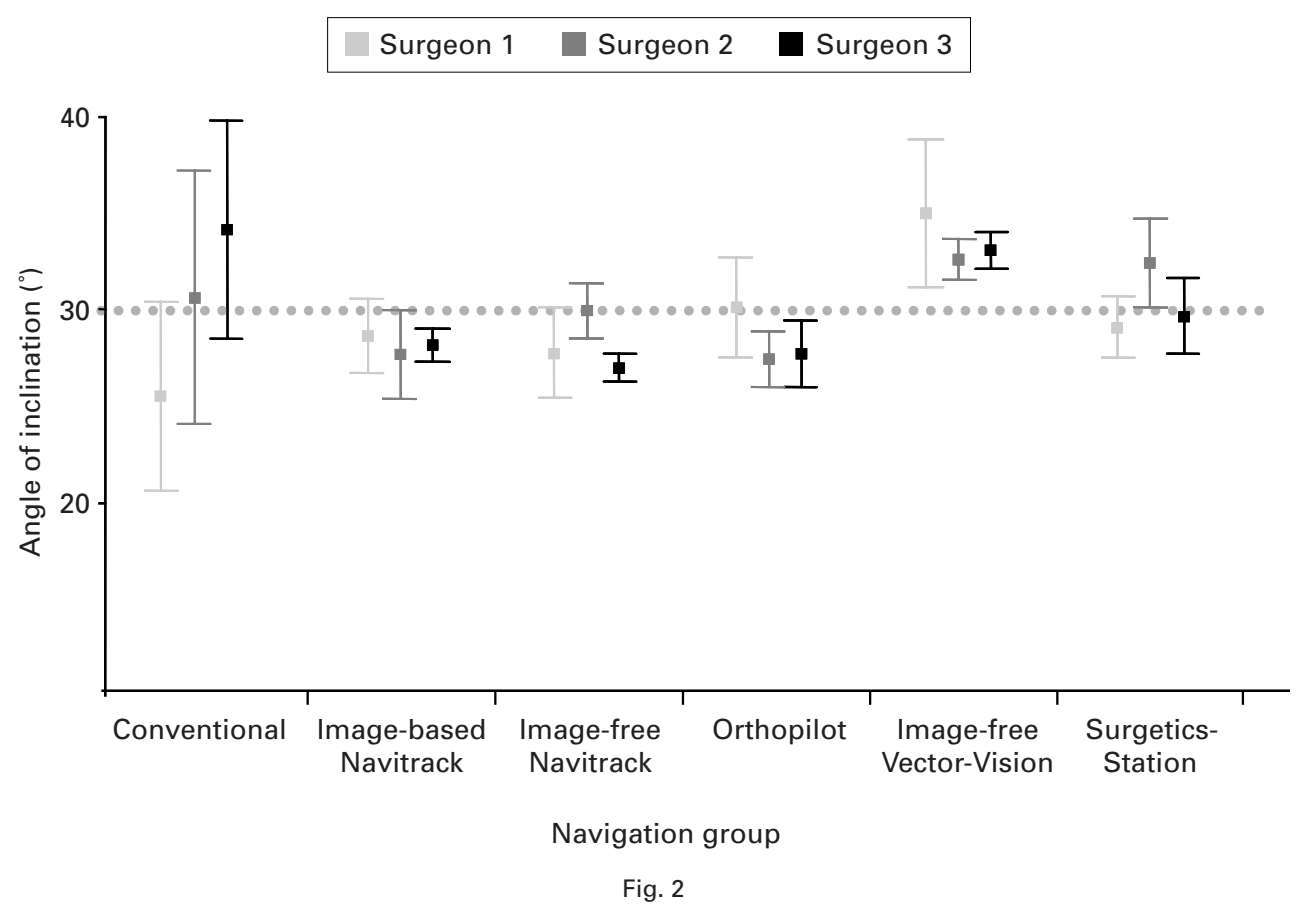

Graph showing the angle of inclination vs the surgeon and navigation group ( $30^{\circ}$ was planned).

The independent variables were the surgeons, and the different methods of implantation (the five navigation systems, and the conventional method), while the dependent variables were the time taken, inclination, anteversion and the difference between the planned angles and the angles that were achieved. For the difference between the planned location of the centres of the acetabular component and that achieved, a Scheffe test ${ }^{42}$ was performed as a post-hoc test when applicable. Pearson correlation coefficients $\left(r_{p}\right)$ were calculated for the comparison of the surgeons' estimate of the position of the acetabular component and the measured positions.

\section{Results}

Surgeon 3 was significantly faster at performing the surgery ( $\mathrm{p}<0.001)$ for the conventional method, image-free and image-based (Fig. 1). The factor 'surgeon' did not significantly influence inclination ( $\mathrm{p}=0.537$, Fig. 2) or anteversion ( $\mathrm{p}=0.336$, Fig. 3 ). The variable 'implantation method' was significant for inclination $(\mathrm{p}=0.001)$ and anteversion $(\mathrm{p}=$ 0.001).

The mean procedure duration for the last sample of a series for all surgeons was 6.44 mins (SD 1.56) in the navigated groups and 3.34 mins (SD 1.15) in the conventional group.

In the conventional group surgeon 2 achieved a mean angle of inclination $\left(31^{\circ}, \mathrm{SD} 6.9\right)$ that was quite well matched with the selected angle. Surgeon 1 implanted the components with too little inclination and surgeon 3 with too great an inclination (Fig. 2). There was more variance of the angle of inclination within the conventional group compared with the computer-assisted surgery groups.

Within the computer-assisted surgery groups, the smallest errors in inclination were observed in the SurgeticsStation system. In comparison, the image-based Navitrack had lower angles of inclination $(\mathrm{p}=0.53)$ and the VectorVision system, significantly higher angles ( $\mathrm{p}=0.042$, Fig. 2 ).

In the conventional group of implantations all the surgeons had lower angles of anteversion than those planned (Fig. 3). Surgeon 1 had the highest variance. In the computer-assisted surgery groups the smallest errors were observed using the Orthopilot system. Compared with this system, the VectorVision had lower angles of anteversion $(\mathrm{p}=0.043)$.

The correlation coefficients between the angles estimated by the surgeons and the measured angles were more accurate for inclination $\left(r_{p}=0.636, p<0.001\right)$ than for anteversion $\left(r_{p}=0.160, p=0.132\right)$.

The position of the component, as indicated by the length of the malposition vector between the planned and the actual location of the centre, was not significantly different for all the surgeons in the conventional group ( $\mathrm{p}=$ $0.966)$. There were statistically-significant differences in the computer-assisted surgery groups. The image-free Navitrack group had smaller errors when compared with the conventional, and the other computer-assisted surgery systems ( $p=0.001)$. The image-based Navitrack and the VectorVision groups had higher errors ( $\mathrm{p} \leq 0.001$, Fig. 4). 


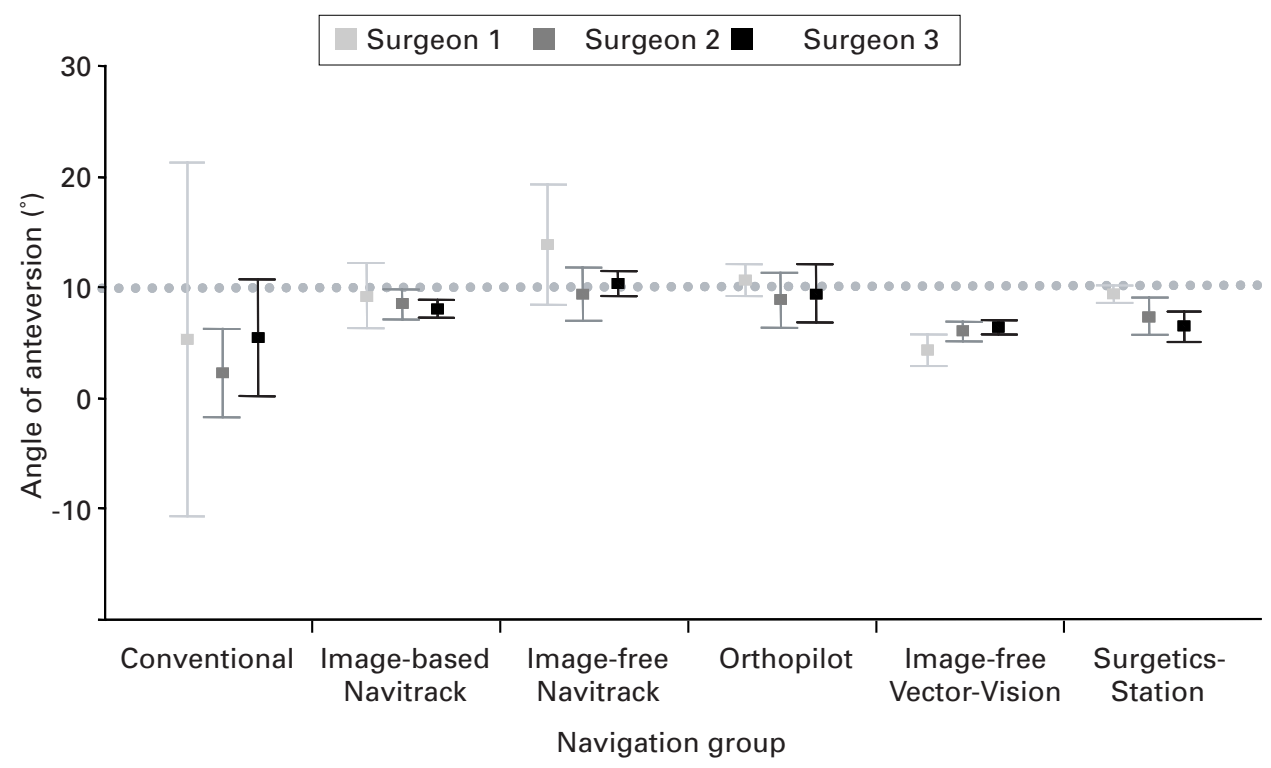

Fig. 3

Graph showing the angle of anteversion vs the surgeon and navigation group ( $10^{\circ}$ was planned).

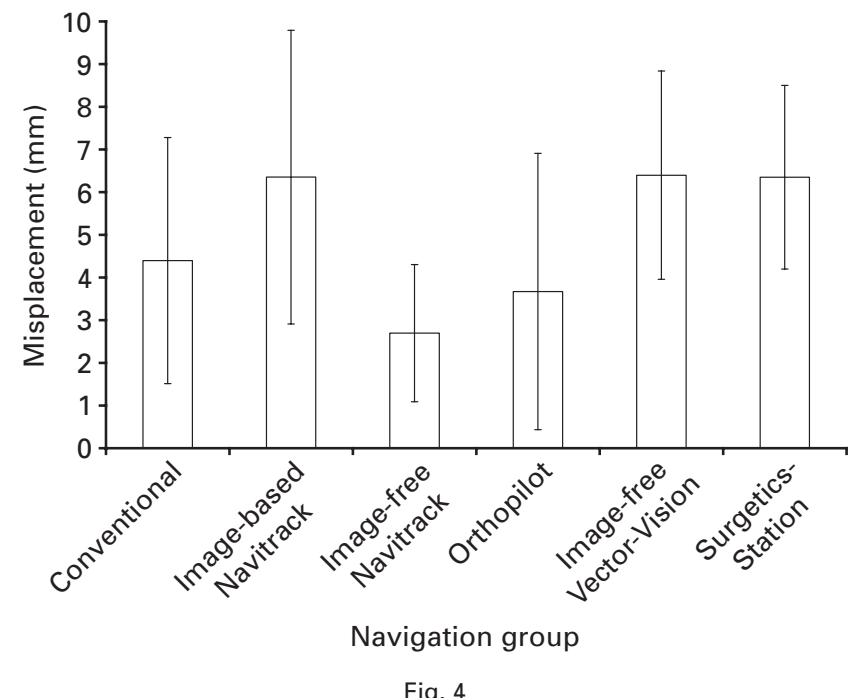

Graph showing the malposition of the component (lengths of the vector between planned and reamed centre) vs navigation group.

\section{Discussion}

Dislocation of a total hip replacement may be caused by inaccurate positioning of the acetabular component. ${ }^{1,3-5}$ If the component is implanted within the safe zone, for both inclination and anteversion, the rate of dislocation can be reduced from $5 \%$ to $1 \% .^{5}$ The safe zone has been revised by Yoshimine ${ }^{43}$ to allow for range of movement, impingement and wear. Yoshimine regards anteversion as the main factor. ${ }^{43}$ Our study shows that the surgeons' estimate of the angle of anteversion did not correlate well with the meas- ured angles. The variation was high and many components were placed outside the safe zone.

The time taken for the surgery was significantly influenced by the surgeon, but surgeon 3, who was the most experienced and quickest, did not produce the best results. This is in contrast to the common criticism of computerassisted surgery that it may only be required by inexperienced surgeons. ${ }^{44,45}$

The differences in orientation of the acetabular component between the computer-assisted surgery systems were not, for the most part, significant but the angle of inclination achieved with the VectorVision system was smaller when compared with the rest. This could be a systematic problem related to having a different algorithm for pelvic orientation. The image-based Navitrack had better results compared with the conventional group. The other computer-assisted surgery systems demonstrated greater malposition than the conventional group. The mean error was 6.39 $\mathrm{mm}$ (SD 2.44), which is not clinically relevant. This could have been caused by the surgeon watching the monitor instead of the surgical field. The significantly lower misplacement in the image-free group indicates that preoperative CT may not be required.

After the initial learning curve the extra time taken for computer-assisted surgery was approximately three minutes when compared with the conventional technique. This does not increase morbidity or the cost of surgery.

The accuracy of placement of the acetabular component in the computer-assisted surgery groups was achieved in a technically ideal situation. During live surgery, errors caused by faulty referencing and the possibility of shutdown of the system have to be considered. 
We chose to use a number of different systems of computer-assisted surgery in order to be able to draw conclusions about navigation in general, rather than one specific system. ${ }^{25}$ The object of our study was not to promote one system at the expense of others, but we could not entirely eliminate bias.

We used a simplified model but there was no indication that this made the surgery easier, or more difficult.

The use of computer navigation allows the surgeon to place the acetabular component with less variation of inclination and anteversion, although this does not necessarily reflect the level of experience of the surgeon.

No benefits in any form have been received or will be received from a commercial party related directly or indirectly to the subject of this article.

\section{References}

1. Coventry MB, Beckenbaugh RD, Nolan DR, Ilstrup DM. 2,012 total hip arthroplasties: a study of postoperative course and early complications. J Bone Joint Surg [Am] 1974;56-A:273-84.

2. Ilstrup DM, Nolan DR, Beckenbaugh RD, Coventry MB. Factors influencing the results in 2,012 total hip arthroplasties. Clin Orthop 1973;95:250-62.

3. Fackler CD, Poss R. Dislocation in total hip arthroplasties. Clin Orthop 1980;151 169-78.

4. Kennedy JG, Rogers WB, Soffe KE, et al. Effect of acetabular component orientation on recurrent dislocation, pelvic osteolysis, polyethylene wear, and component migration. J Arthroplasty 1998;13:530-4.

5. Lewinnek GE, Lewis JL, Tarr R, Compere CL, Zimmerman JR. Dislocations after total hip-replacement arthroplasties. J Bone Joint Surg [Am] 1978;60-A:217-20.

6. Schmalzried TP, Guttmann D, Grecula M, Amstutz HC. The relationship between the design, position, and articular wear of acetabular components inserted without cement and the development of pelvic osteolysis. J Bone Joint Surg [Am] 1994;76-A 677-88.

7. Gambera, Carta $\mathbf{S}$, Crainz $\mathbf{E}$, et al. Metallosis due to impingement between the socket and the femoral head in a total hip prosthesis: a case report. Acta Biomed Ateneo Parmense 2002;73:85-91.

8. Kummer FJ, Shah S, Iyer S, DiCesare PE. The effect of acetabular cup orientations on limiting hip rotation. J Arthroplasty 1999;14:509-13.

9. Kobayashi S, Takaoka K, Tsukada A, Ueno M. Polyethylene wear from femoral bipolar neck-cup impingement as a cause of femoral prosthetic loosening. Arch Orthop Trauma Surg 1998;117:390-1.

10. Yamaguchi M, Bauer TW, Hashimoto Y. Three-dimensional analysis of multiple wear vectors in retrieved acetabular cups. J Bone Joint Surg [Am] 1997;79-A: 1539-44.

11. Nolte LP, Visarius H, Arm E, et al. Computer-aided fixation of spinal implants. J Image Guid Surg 1995;1:88-93.

12. Foley KT, Smith MM. Image-guided spine surgery. Neurosurg Clin N Am 1996;7: 171-86.

13. Nolte LP, Zamorano L, Visarius $\mathbf{H}$, et al. Clinical evaluation of a system for precision enhancement in spine surgery. Clin Biomech (Bristol, Avon) 1995;10:293-303.

14. Nolte LP, Zamorano LJ, Jiang Z, et al. Image-guided insertion of transpedicular screws: a laboratory set-up. Spine 1995;20:497-500.

15. Nolte LP, Visarius H, Arm E, et al. Computer-aided fixation of spinal implants. J Image Guid Surg 1995;1:88-93.

16. Berger RA. Total hip arthroplasty using the minimally invasive two-incision approach. Clin Orthop 2003;417:232-41.

17. Berger RA, Jacobs JJ, Meneghini RM, et al. Rapid rehabilitation and recovery with minimally invasive total hip arthroplasty. Clin Orthop 2004;429:239-47.

18. Berger RA. Minimally invasive THR using two incisions. Orthopedics 2004;27:382-3.

19. Goldstein WM, Branson JJ. Posterior-lateral approach to minimal incision total hip arthroplasty. Orthop Clin North Am 2004;35:131-6.
20. DiGioia AM III, Plakseychuk AY, Levison TJ, Jaramaz B. Mini-incision technique for total hip arthroplasty with navigation. J Arthroplasty 2003;18:123-8

21. Howell JR, Masri BA, Duncan CP. Minimally invasive versus standard incision anterolateral hip replacement: a comparative study. Orthop Clin North Am 2004;35: 153-62.

22. Nogler M. Navigated minimal invasive total hip arthroplasty. Surg Technol Int 2004 12:259-62.

23. Honl M, Dierk 0, Gauck C, et al. Comparison of robotic-assisted and manua implantation of a primary total hip replacement: a prospective study. J Bone Joint Surg $[A m] 2003 ; 85-A: 1470-8$.

24. Kalteis T, Handel M, Herold T, et al. Greater accuracy in positioning of the acetabular cup by using an image-free navigation system. Int Orthop 2005;29:272-6.

25. Kalteis $\mathbf{T}$, Handel $\mathbf{M}$, Bathis $\mathbf{H}$, et al. Imageless navigation for insertion of the acetabular component in total hip arthroplasty: is it as accurate as CT-based navigation? J Bone Joint Surg [Br] 2006;88-B:163-7.

26. Jaramaz B, Eckman K. Virtual reality simulation of fluoroscpic navigation. Clin Orthop 2006;442:30-4.

27. Grutzner PA, Zheng G, Langlotz $\mathbf{U}$, et al. C-arm based navigation in total hip arthroplasty-background and clinical experience. Injury 2004;35(Suppl 1):90-5

28. Widmer KH, Grutzner PA. Joint replacement-total hip replacement with CT-based navigation. Injury 2004;35(Suppl 1):9

29. Kalteis T, Backmann J, Herold T, et al. Accuracy of an image-free cup navigation system: an anatomical study. Biomed Tech (Berl) 2004;49:257-62.

30. Kiefer H. OrthoPilot cup navigation: how to optimise cup positioning? Int Orthop 2003;27(Suppl 1):37-42.

31. Wentzensen A, Zheng G, Vock B, et al. Image-based hip navigation. Int Orthop 2003;27(Suppl 1):43-6.

32. Bernsmann K, Langlotz U, Ansari B, Wiese M. Computer-assisted navigated cup placement of different cup types in hip arthroplasty: a randomised controlled trial. Z Orthop Ihre Grenzgeb 2001;139:512-17

33. Digioia AM 3rd, Jaramaz B, Plakseychuk AY, et al. Comparison of a mechanical acetabular alignment guide with computer placement of the socket. J Arthroplasty 2002;17:359-64

34. Leenders T, Vandevelde D, Mahieu G, Nuyts R. Reduction in variability of acetabular cup abduction using computer assisted surgery: a prospective and randomized study. Comput Aided Surg 2002;7:99-106

35. Hube R, Birke A, Hein W, Klima S. CT-based and fluroscopy-based navigation for cup implantation in total hip arthroplasty (THA). Surg Technol Int 2003;11:275-80.

36. Amiot LP, Poulin F. Computed tomography-based navigation for hip, knee, and spine surgery. Clin Orthop 2004:421:77-86.

37. Kalteis $\mathbf{T}$, Handel $\mathbf{M}$, Herold $\mathbf{T}$, et al. Position of the acetabular cup-accuracy of radiographic calculation compared to CT-based measurement. Eur J Radiol 2006;58: 294-300.

38. Nogler M, Kessler 0, PrassI A, et al. Reduced variability of acetabular cup positioning with use of an imageless navigation system. Clin Orthop 2004;426:159-63.

39. Dorr LD, Hisjiki Y, Wan Z, Newton D, Yun A. Development of imageless computer navigation for acetabular component position in total hip replacement. lowa Orthop $J$ 2005:25:1-9.

40. Lazovic D, Kaib N. Results with navigated bicontact total hip arthroplasty. Orthopedics 2005;28:1227-33

41. Wixson RL, MacDonald MA. Total hip arthroplasty through a minimal posterior approach using imageless computer-assisted hip navigation. J Arthroplasty 2005;20: $51-6$

42. Bird KD. Confidence intervals for effect sizes in analysis of variance. Educational and Psychological Measurement 2002:62:197-226.

43. Yoshimine $\mathbf{F}$. The influence of the oscillation angle and the neck anteversion of the prosthesis on the cup safe-zone that fulfills the criteria for range of motion in total hip replacements: the required oscillation angle for an acceptable cup safe-zone. J Biomech 2005;38:125-32

44. Katz JN, Barrett J, Mahomed NN, et al. Association between hospital and surgeon procedure volume and the outcomes of total knee replacement. J Bone Joint Surg [Am] 2004:86-A:1909-16.

45. Solomon DH, Losina E, Baron JA, et al. Contribution of hospital characteristics to the volume-outcome relationship: dislocation and infection following total hip replacement surgery. Arthritis Rheum 2002:46:2436-44. 